A) Check for updates

Cite this: Food Funct., 2021, 12, 4005

\section{Toxicological and anti-tumor effects of a linden extract (Tilia platyphyllos Scop.) in a HPV16-transgenic mouse model}

\author{
Tiago Ferreira, (D) $\dagger^{a}$ Elisabete Nascimento-Gonçalves, $\dagger^{\mathrm{T}}$ Sara Macedo, (iD) a \\ Inês Borges, (D) a Adelina Gama, ${ }^{b}$ Rui M. Gil da Costa, (iD a,c,d,e Maria J. Neuparth, ${ }^{f}$ \\ Germano Lanzarin, (iD a Carlos Venâncio, ${ }^{a}$ Luís Félix, ${ }^{a}{ }^{a}$ Isabel Gaivão, ${ }^{\text {h }}$ \\ Antonieta Alvarado, ${ }^{a, i}$ Maria J. Pires, ${ }^{a}$ Margarida M. S. M. Bastos, (iD d \\ Rui Medeiros, ${ }^{c, j, k, l, m}$ António Nogueira, iD n Lillian Barros, (ID n \\ Isabel C. F. R. Ferreira, (D) n Eduardo Rosa ${ }^{a}$ and Paula A. Oliveira (D) *a
}

Tilia platyphyllos Scop. is a popular broad-leaved tree, native to Central and Southern Europe. Hydroethanolic extracts rich in phenolic compounds obtained from T. platyphyllos Scop. have shown in vitro antioxidant, anti-inflammatory and antitumor properties. The aim of this work was to evaluate the therapeutic properties of a hydroethanolic extract obtained from T. platyphyllos in HPV16-transgenic mice. The animals were divided into eight groups according to their sex and phenotype. Four groups of female: HPV+ exposed to linden (HPV linden; $n=6$ ), HPV+ (HPV water; $n=4)$, HPV- exposed to linden (WT linden; $n=5)$ and HPV- (WT water; $n=4)$ and four groups of male: HPV+ exposed to linden (HPV linden; $n=5)$, HPV+ (HPV water; $n=5)$, HPV- exposed to linden (WT linden; $n=5)$ and HPV- (WT water; $n=7$ ). The linden (Tilia platyphyllos Scop.) extract was orally administered at a dose of $4.5 \mathrm{mg} / 10 \mathrm{~mL}$ per animal (dissolved in water) and changed daily for 33 days. The hydroethanolic extract of T. platyphyllos consisted of protocatechuic acid and (-)-epicatechin as the most abundant phenolic acid and flavonoid, respectively, and was found to be stable during the studied period. In two male groups a significant positive weight gain was observed but without association with the linden extract. Histological, biochemical, and oxidative stress analyses for the evaluation of kidney and liver damage support the hypothesis that the linden extract is safe and well-tolerated under the present experimental conditions. Skin histopathology does not demonstrate the chemopreventive effect of the linden extract against HPV16-induced lesions. The linden extract has revealed a favourable toxicological profile; however, additional studies are required to determine the chemopreventive potential of the linden extract.
Received 21st January 2021 Accepted 15th March 2021 DOI: $10.1039 / \mathrm{d} 1 \mathrm{fo} 00225 \mathrm{~b}$ rsc.li/food-function
Europe, this plant species belongs to the Malvacaeae family. ${ }^{3}$ T. platyphyllos Scop. is characterized by fast growth, positive impact on soil fertility and great resistance to unfavourable external conditions. ${ }^{4}$ Linden has important biological pro-
Tilia platyphyllos Scop., popularly known as linden, is a deciduous broad-leaved tree. ${ }^{1,2}$ Native to Central and Southern

\footnotetext{
${ }^{h}$ Department of Genetic and Biotechnology and CECAV, UTAD, Vila Real, Portugal ${ }^{i}$ Faculty of Veterinary Medicine, Lusophone University of Humanities and Technologies, Lisbon, Portugal

${ }^{j}$ Faculty of Medicine, University of Porto (FMUP), Porto, Portugal

${ }^{k}$ Virology Service, Portuguese Oncology Institute of Porto (IPO Porto), Porto, Portugal

${ }^{l}$ CEBIMED, Faculty of Health Sciences, Fernando Pessoa University, Porto, Portugal ${ }^{m}$ Research Department of the Portuguese League Against Cancer-Regional Nucleus of the North (Liga Portuguesa Contra o Cancro-Núcleo Regional do Norte), Porto, Portugal

${ }^{n}$ Centro de Investigação de Montanha (CIMO), Instituto Politécnico de Bragança, Campus de Santa Apolónia, 5300-253 Bragança, Portugal

$\dagger$ Both of them are first authors.
} 
perties such as diuretic, antispasmodic, sedative, antioxidant, hepatoprotective and anti-neuralgic properties. $^{5}$ Protocatechuic acid and (-)-epicatechin are the most abundant phenolic acid and flavonoid in T. platyphyllos Scop. respectively. ${ }^{3}$ A hydroethanolic extract rich in phenolic compounds obtained from T. platyphyllos Scop. has demonstrated antioxidant, anti-inflammatory and antitumor effects in vitro. ${ }^{3}$ Several animal experiments indicate that protocatechuic acid may have protective effects against epithelial malignancies in different tissues $^{6}$ such as bladder ${ }^{7}$ and skin cancers. $^{8}$ Moreover, epicatechin has demonstrated a significant antioxidative activity and has shown cardioprotective, anti-diabetic and neuroprotective activities. ${ }^{9}$ Human papillomavirus (HPV) is an infectious agent responsible for $5 \%$ of all human cancers, and is transmitted by direct contact. ${ }^{10} \mathrm{HPV}$ belongs to the Papillomaviridae family and is an icosahedral and nonenveloped virus with circular double-strand DNA. The viral genome consists of three regions: the early region, the late region and the long control region. ${ }^{11,12}$ This virus can be divided into two groups: high-risk and low-risk types. The latter causes warts that are eliminated by the immune system whereas the high-risk HPVs (namely the HPV16 and 18 types), after persistent infection, are the major cause of anogenital and oropharyngeal cancers in both sexes. ${ }^{13}$ The HPV16 early genomic region encodes the E5, E6 and E7 oncoproteins that are essential for the development of malignant lesions whereas the late region encodes the capsid proteins. ${ }^{13,14}$ For this reason, our team chose a transgenic mouse model carrying the complete HPV16 early region ${ }^{15}$ to study the effects of T. platyphyllos Scop. when administered orally to HPV16-transgenic mice. The aims of these experiments were to test the potential chemopreventive effects of the extract against the development of HPV16-induced lesions and to determine its in vivo toxicity in this animal model.

\section{Methods}

\subsection{Sample preparation}

The aerial parts of Tilia platyphyllos Scop. were provided by Cantinho das Aromáticas, organic farmers from Vila Nova de Gaia (Portugal). The dried samples were ground into powder and subjected to an extraction procedure at room temperature $\left(\approx 25{ }^{\circ} \mathrm{C}\right)$ as follows: $5 \mathrm{~g}$ of $\mathrm{T}$. platyphyllos was extracted under magnetic stirring for $1 \mathrm{~h}$ in the dark with $150 \mathrm{~mL}$ of ethanol : water $(80: 20, \mathrm{v} / \mathrm{v})$, filtered and re-extracted under the same conditions. Then, ethanol was removed using a rotary evaporator (Büchi R-210, Flawil, Switzerland), and water was removed by lyophilisation. The concentration used to feed the animals was determined based on the $\mathrm{IC}_{50}$ value obtained in in vitro anti-inflammatory studies performed by us previously $(225 \mu \mathrm{g}$ $\mathrm{mL}^{-1}$ ), and it was decided to administrate $2 \times$ the $\mathrm{IC}_{50}$ concentration to guarantee the phenolic compound concentration. ${ }^{3}$ Therefore, the extract was dissolved in water at a concentration of $450 \mu \mathrm{g} \mathrm{mL}^{-1}$ (4.5 mg in $10 \mathrm{~mL}$ of water), and the solution was renewed every day for the in vivo studies.

\subsection{Profiles of phenolic compounds and stability of the aqueous extracts}

The phenolic compounds were determined using a Dionex Ultimate 3000 UPLC (Thermo Scientific, San Jose, CA, USA), accolated with a diode-array detector (DAD, 280, 330 and $370 \mathrm{~nm}$ as preferred wavelengths), and a mass detector equipped with an ESI source (Linear Ion Trap LTQ XL, Thermo Finnigan, San Jose, CA, USA) following a previously described procedure. $^{16}$ The identification of different phenolic compounds was performed by comparison with the available commercial standards, or tentatively identified using the reported data from the literature. For quantitative analysis, a calibration curve for each available phenolic standard was constructed based on the UV-Vis signal or when no commercial standard was available a similar compound from the same phenolic group was used as a standard and the results were expressed in $\mathrm{mg} \mathrm{mL} \mathrm{m}^{-1}$ of extract. The stability of the drinking water ( $5 \mathrm{mg} \mathrm{mL}^{-1}$ ) was evaluated during 5 consecutive days at room temperature, and analyzed daily using an LC-DAD-ESI/MS system to visualize if any possible degradation of the phenolic compounds has occurred.

\subsection{Animals}

This study was approved by the University of Trás-os-Montes and Alto Douro Ethics committee (approval no. 10/2013) and the Portuguese Veterinary Authorities (approval no. 0421/000/ $000 / 2014)$. This experimental trial followed the national legislation (Decree-Law 113/2013, August 7) and European Directive 2010/63/EU on the protection of animals for experiments. Forty-two K14HPV16 mice on an FVB/n background [22 wildtype (HPV16-) and 20 hemizygotic (HPV16+)] with 8 weeks of age were selected for this experimental assay. This study was performed with both female and male mice (12 males and 10 females, wild-type; and 10 males and 10 females, transgenic). This animal model was generously donated by Dr. Jeffrey Arbeit and Dr. Douglas Hanahan through the USA National Cancer Institute Mouse Repository, University of California. The animals were maintained under controlled conditions of temperature $\left(23 \pm 2^{\circ} \mathrm{C}\right)$ and relative humidity $(50 \pm 10 \%)$, with a photoperiod cycle of $12 \mathrm{~h}$ light and $12 \mathrm{~h}$ darkness. All animals had ad libitum access to standard diet (Mucedola 4RF21 Certificate, Milan, Italy) and water and were housed in polycarbonate cages with corncob bedding (Ultragene, Santa Comba Dão, Portugal). Environmental enrichment was placed in each cage and the cages were cleaned weekly.

\subsection{Experimental design}

The linden extract was administered orally at a dose of $4.5 \mathrm{mg} /$ $10 \mathrm{~mL}$ per animal (dissolved in water) and changed daily. The animals were divided into eight groups according to their sex and phenotype. Four groups of female: HPV+ exposed to linden (HPV linden; $n=6$ ), HPV+ (HPV water; $n=4$ ), HPVexposed to linden (WT linden; $n=5)$ and HPV- (WT water; $n=$ 4) and four groups of male: HPV+ exposed to linden (HPV linden; $n=5$ ), HPV+ (HPV water; $n=5$ ), HPV- exposed to 
linden (WT linden; $n=5$ ) and HPV- (WT water; $n=7$ ). The assay lasted 33 days and during this time the animals' health was checked daily. Their body weights and food intake were registered weekly and water consumption was recorded daily. At the end of the experimental period, all animals were sacrificed by intraperitoneal administration of an overdose of xylazine-ketamine, followed by cardiac puncture and exsanguination, according to the Federation of European Laboratory Animal Science Association (FELASA) guidelines. ${ }^{17}$ During necropsy, the ear skin and internal organs were collected, weighed and fixed in 10\% neutral formaldehyde for histological analysis.

\subsection{Haematology}

The blood samples were centrifuged (12 $000 \mathrm{rpm}$ for $5 \mathrm{~min}$ ) in capillary tubes for the determination of microhematocrit values. Also, the blood samples were placed in heparin tubes and centrifuged at $3000 \mathrm{rpm}$ for $15 \mathrm{~min}$ to obtain plasma. The plasma was frozen at $-80{ }^{\circ} \mathrm{C}$ until use. Using an autoanalyzer (Prestige 24i, Cornay PZ) the concentration of alanine aminotransferase (ALT), aspartate aminotransferase (AST), creatinine and urea were determined to verify the hepato- and nephrotoxic effects.

\subsection{Histology}

Fixed skin, kidney, liver and spleen samples were routinely processed for light microscopy. The paraffin-embedded samples were cut into $2 \mu \mathrm{m}$ sections and stained with hematoxylin and eosin for histological examination under a light microscope. Skin ear lesions were classified as normal skin, epidermal hyperplasia (mild, moderate or marked), dysplasia and carcinoma in situ (CIS). ${ }^{18}$ The kidney, liver and spleen tissue samples were histologically evaluated for morphological alterations, including the presence of inflammation or necrosis.

\subsection{Oxidative stress}

To determine the liver and kidney oxidative stress parameters, the frozen samples were processed as previously described. ${ }^{19}$ For protein determination, the supernatant was collected, and the protein content was measured at $280 \mathrm{~nm}$ using a Take3 Multi-Volume plate (Take3 plate, BioTek Instruments, USA). All samples were analysed in duplicate using $20 \mu \mathrm{L}$ of tissue at $30{ }^{\circ} \mathrm{C}$ using a PowerWave XS2 microplate scanning spectrophotometer (BioTek Instruments, USA) or a Varian Cary Eclipse (Varian, USA) spectrofluorometer. The determinations were assayed with modifications according to previous studies. $^{20,21}$ Reactive oxygen species (ROS) were measured using the probe $2^{\prime}, 7^{\prime}$-dihlorofluoresceindiacetate (DCFH-DA), the fluorescence intensity was measured with excitation and emission at $488 \mathrm{~nm}$ and $510 \mathrm{~nm}$, respectively and expressed as $\mu \mathrm{mol}$ DCF $\mathrm{mg}$ protein-1 based on a standard of DCF $(0-1 \mathrm{mM}){ }^{22}$ Superoxide dismutase (SOD) activity was measured through the inhibition of photochemical reduction of nitroblue tetrazolium in the reaction with the addition of xanthine-oxidase $(530 \mathrm{~nm}){ }^{23}$ SOD of bovine erythrocytes was used to obtain a standard curve (0-30 $\left.\mathrm{U} \mathrm{mL}^{-1}\right)$ and the results were expressed as $\mathrm{U} \mathrm{mg}^{-1}$ protein. Catalase activity (CAT) was estimated at $240 \mathrm{~nm}$ (ref. 24) being calculated using a bovine catalase standard curve $\left(0-30 \mathrm{U} \mathrm{mL}^{-1}\right)$ and the results were expressed in $\mathrm{U} \mathrm{mg}^{-1}$ protein. The glutathione S-transferase (GST) activity was determined by combining 2,4-dinitrochlorobenzene (CDNB) with reduced glutathione $(340 \mathrm{~nm})^{25}$ and the results were expressed as nmol $\mathrm{CDNB} / \mathrm{min}^{\mathrm{mg}} \mathrm{g}^{-1}$ of protein using the extinction coefficient for CDNB of $9.6 \mathrm{mM}^{-1} \mathrm{~cm}^{-1}$. The concentrations of the reduced (GSH) and oxidized (GSSG) glutathione states were determined based on the derivatization with ortho-phthalaldehyde. The fluorescence intensity was measured with excitation and emission at $320 \mathrm{~nm}$ and $420 \mathrm{~nm}$, respectively. ${ }^{26}$ Concentrations were calculated based on the GSH and GSSG standard curves (0-1 mM). The coefficient between GSH and GSSG or the oxidative stress index (OSI) was then calculated. Malondialdehyde (MDA) levels, as an indicator of lipid peroxidation, were determined by a thiobarbituric acid (TBA) based method (530 nm and $600 \mathrm{~nm}$ nonspecific). ${ }^{27}$ The MDA was calculated according to a standard curve $(0-500 \mu \mathrm{M})$ of malondialdehyde bis(dimethyl acetal) and the results were expressed as $\mu \mathrm{mol}$ MDA per mg of protein.

\subsection{Statistical analysis}

The ponderal gain was calculated as previously described. ${ }^{28}$ Relative organ weights were calculated by the ratio of the animals' organ weights to their body weights. The Kolmogorov-Smirnov test was performed to verify the normality of the data. Analysis of variance (ANOVA) was used with the Bonferroni test and the data were expressed as mean $\pm \mathrm{SE}$ (standard error). The histological results were analysed using a Chi-square test. The analyses were performed using IBM SPSS version 25 (Statistical Package for the Social Sciences, Chicago, Illinois, USA) and the results were considered statistically significant when $p<0.05$.

\section{Results}

\subsection{Phenolic composition}

The chromatographic compound characteristics (retention time, $\lambda_{\max }$ in the UV-Vis, and mass spectral data) and tentative identification of the phenolic compounds present in the T. platyphyllos hydroethanolic extract are presented in Table 1. Eighteen compounds were detected, of which sixteen were flavonoids (three flavan-3-ols and eleven flavonols, one flavanone and one flavone) and two were phenolic acids. These compounds were previously found in ethanol extracts obtained from the aerial parts of T. platyphyllos, as described by Jabeur et al. (2017). ${ }^{3}$ As in this study, (-)-epicatechin and protocatechuic acid were the most abundantly present flavonoid and phenolic acid respectively. The stability of these extracts was studied during 5 consecutive days and it was found that on day 4 the concentration of phenolic compounds began to decrease (Table 1). Therefore, the feeding water was main- 


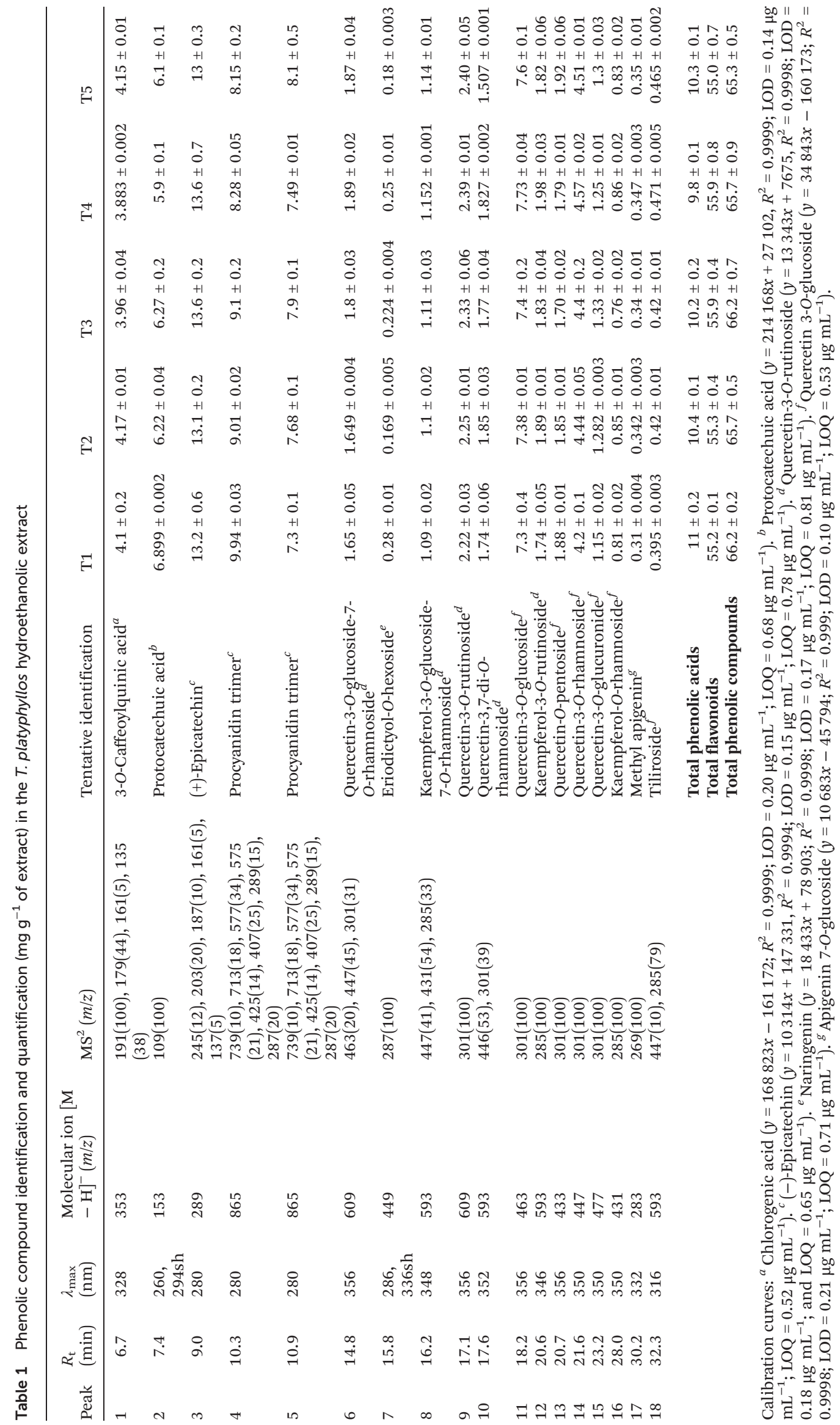



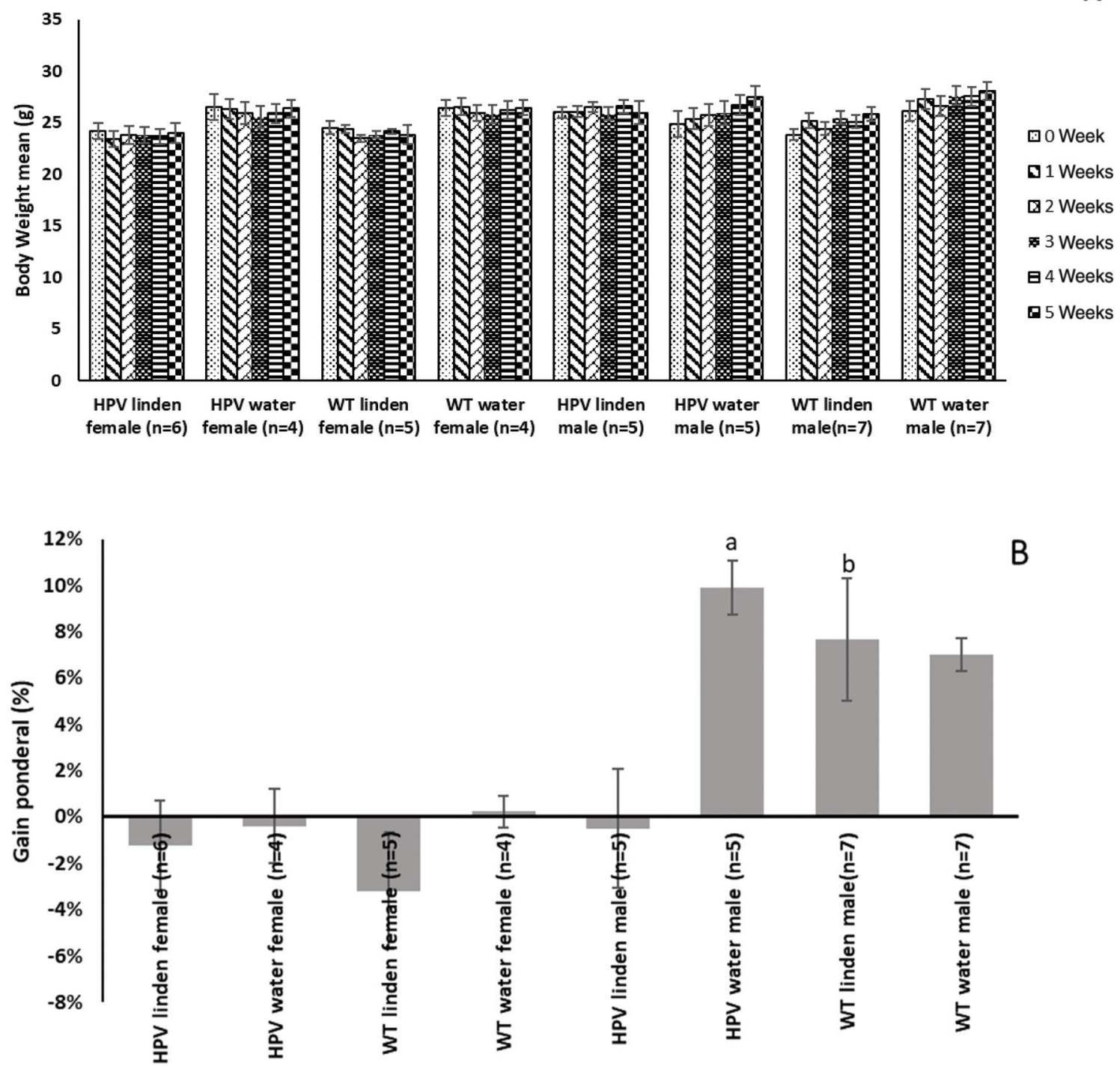

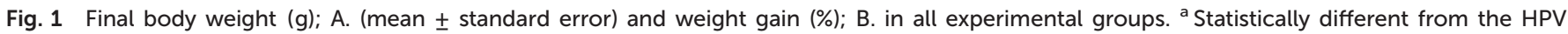
linden male group $(p<0.05) ;{ }^{b}$ statistically different from the WT linden female group $(p<0.05)$.

tained up to a maximum of 3 days to avoid degradation of those compounds.

\subsection{General findings}

During the experimental work no mortality was recorded. Fig. 1 shows the final body weight and weight gain of animals in the different groups. There were no differences in the mean body weight of the animals. The WT linden female group showed lower weight gain than the WT linden male group ( $p<$ 0.05). Fig. 2 shows the mean values of water consumption at the beginning and at the end of the experimental work. Female animals from the WT linden group showed lower water consumption when compared to the matched control (WT water female group; $4.8 \pm 0.03$ and $6.8 \pm 0.02 \mathrm{~g}$, respectively) ( $p$ $<0.05)$. The food consumption was similar between the groups (data not shown). The relative weights of the internal organs are reported in Table 2. The WT linden-exposed male group and the HPV linden-exposed male group showed higher right kidney relative weight than the WT linden exposed female group and the HPV water exposed male group, respectively $(p<0.05)$.

\subsection{Toxicity evaluation}

The serum biochemical parameters are summarized in Table 3. There were no significant differences between the groups exposed and non-exposed to linden extract. However, in exposed female groups the aspartate aminotransferase (AST) values were higher than in non-exposed female groups, both in wild-type and transgenic groups. There were no significant differences between the groups regarding the microhematocrit values (Table 3). The histological analysis results of skin ear samples are summarized in Table 4. The HPV groups (linden exposed and non-exposed) were characterized by moderate to 


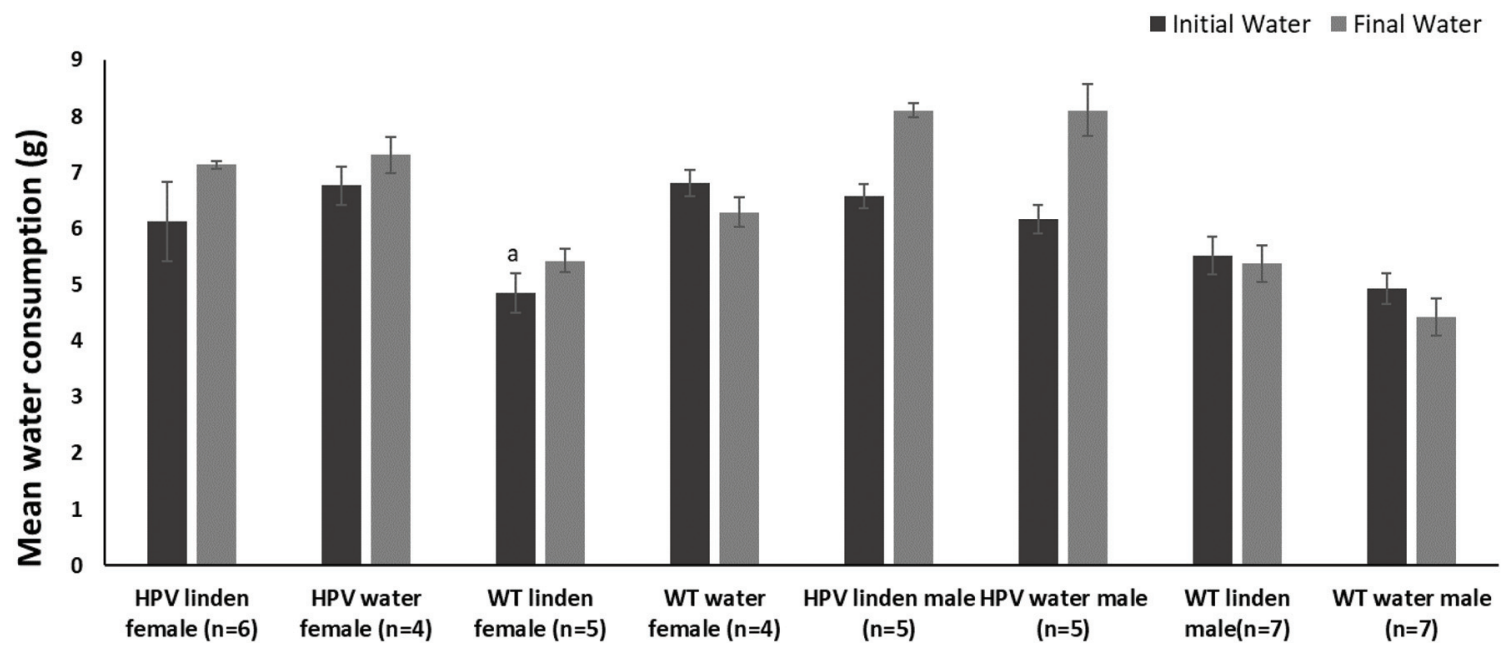

Fig. 2 Consumption (g) of water in all experimental groups (mean \pm standard error); ${ }^{a}$ statistically different from the WT linden female group ( $p<$ 0.05).

Table 2 Relative weight of the internal organs in the experimental groups (mean \pm standard error)

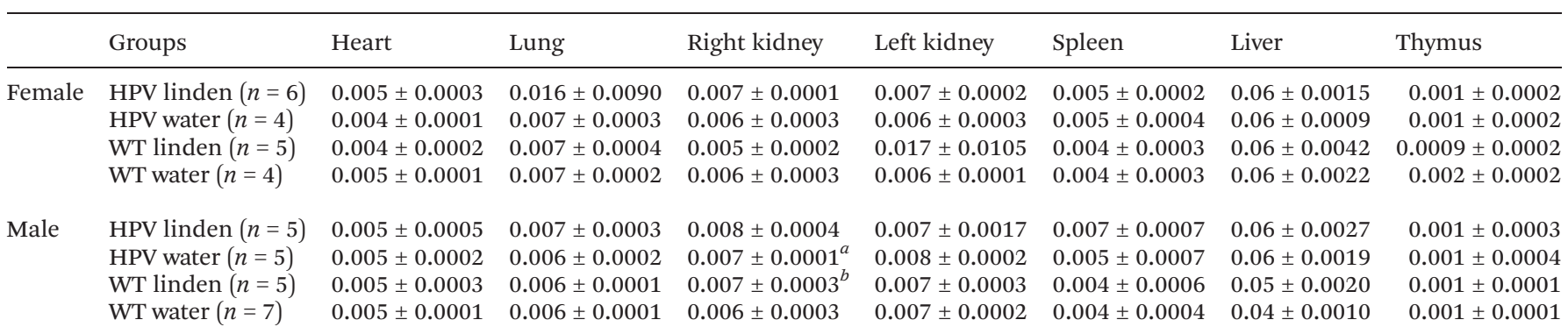

${ }^{a}$ Statistically different from the HPV linden male group $(p<0.05) .{ }^{b}$ Statistically different from the WT linden female group ( $\left.p<0.05\right)$.

Table 3 Microhematocrit $(\mathrm{Ht})$ and serum parameters (mean \pm standard error)

\begin{tabular}{|c|c|c|c|c|c|c|}
\hline & Groups & Ht (\%) & Creatinine $\left(\mathrm{U} \mathrm{L}^{-1}\right)$ & Urea $\left(\mathrm{U} \mathrm{L}^{-1}\right)$ & $\operatorname{ALT}\left(m g \mathrm{dL}^{-1}\right)$ & $\operatorname{AST}\left(\mathrm{mg} \mathrm{dL}^{-1}\right)$ \\
\hline \multirow[t]{3}{*}{ Female } & HPV linden $(n=6)$ & 44.6 & $0.3 \pm 0.2$ & $82.9 \pm 20.8$ & $54.7 \pm 11.2$ & $114.4 \pm 31.1$ \\
\hline & HPV water $(n=4)$ & 44.3 & $0.1 \pm 0.0050$ & $133.2 \pm 35.4$ & $61.8 \pm 7.6$ & $100.1 \pm 2.1$ \\
\hline & WT water $(n=4)$ & 44.5 & $0.4 \pm 0.1$ & $65.8 \pm 13.9$ & $37.2 \pm 1.3$ & $76.7 \pm 8.6$ \\
\hline \multirow[t]{2}{*}{ Male } & HPV linden $(n=5)$ & 47.7 & $0.08 \pm 0.03$ & $97.9 \pm 11.7$ & $46.4 \pm 4.9$ & $79.7 \pm 9.1$ \\
\hline & HPV water $(n=5)$ & 44.3 & $0.3 \pm 0.1$ & $95.8 \pm 17.1$ & $56.8 \pm 8.4$ & $153.1 \pm 29.3$ \\
\hline
\end{tabular}

Statistically significant differences were not found.

marked epidermal hyperplasia, with most animals also exhibiting multifocal dysplasia. Although not significant, the HPV female group not exposed to linden extract showed more epidermal dysplasia than the HPV exposed to linden extract female group (100 vs. 83.3\%, respectively) ( $p>0.05)$ (Fig. 3). A similar pattern was observed in HPV male mice exposed to linden extract, which showed less epidermal dysplasia than animals not exposed ( $80 \%$ vs. $100 \%$, respectively) $(p>0.05)$.
With regard to carcinoma in situ, it was observed in a small number of HPV animals not associated with linden administration. Regarding internal organs, no significant morphological changes were observed across the analysed groups (Table 5). Several animals presented multifocal inflammatory aggregates in the liver and kidneys (less than five aggregates), characterized by the presence of mononuclear or polymorphonuclear cells in both the exposed and non-exposed groups. 
Table 4 Histological evaluation of the ear skin

\begin{tabular}{|c|c|c|c|c|c|c|}
\hline & Groups & Normal & Mild hyperplasia & Moderate to marked hyperplasia & Dysplasia & Carcinoma in situ \\
\hline & HPV water $(n=4)$ & $0(0 \%)$ & $0(0 \%)$ & $4(100 \%)$ & $4(100 \%)$ & $1(25 \%)$ \\
\hline & WT water $(n=4)$ & $2(50 \%)$ & $2(50 \%)$ & $0(0 \%)^{b}$ & $0(0 \%)^{b}$ & $0(0 \%)$ \\
\hline \multirow[t]{2}{*}{ Male } & HPV linden $(n=5)$ & $0(0 \%)$ & $0(0 \%)$ & $5(100 \%)$ & $4(80 \%)$ & $0(0 \%)$ \\
\hline & HPV water $(n=5)$ & $0(0 \%)$ & $0(0 \%)$ & $5(100 \%)$ & $5(100 \%)$ & $1(20 \%)$ \\
\hline
\end{tabular}

${ }^{a}$ Statistically different from the HPV linden female group $(p<0.05) .{ }^{b}$ Statistically different from the HPV water female group $(p<0.05)$. ${ }^{c}$ Statistically different from the HPV linden male group $(p<0.05) .{ }^{d}$ Statistically different from the HPV water male group $(p<0.05)$.
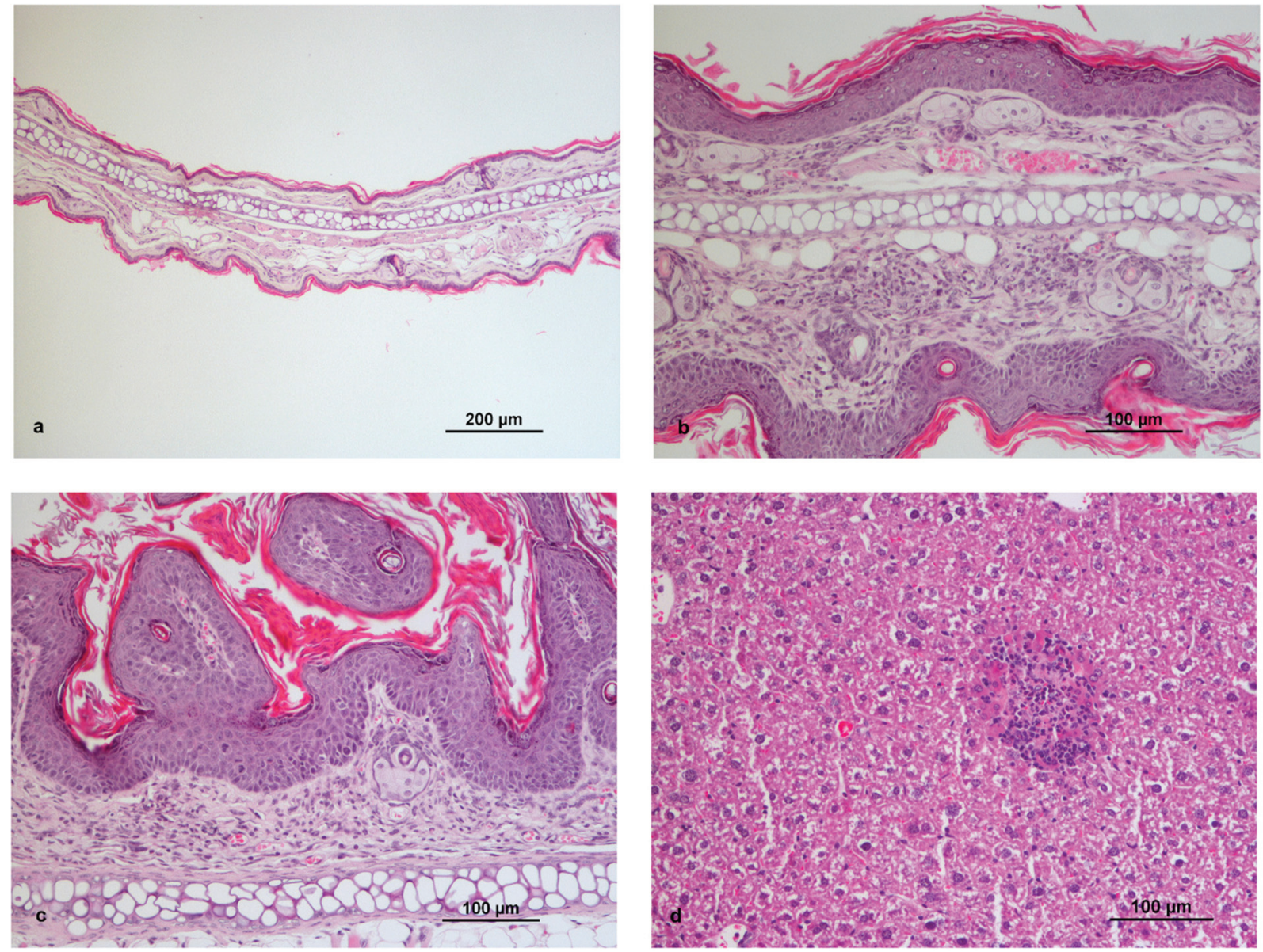

Fig. 3 Histological analysis of mice samples. a. WT linden female mouse showing normal ear skin; b. ear skin of HPV linden female mouse showing moderate to marked epidermal hyperplasia (at the top) and dysplasia (at the bottom), associated with dermal inflammatory infiltrate; c. ear skin of HPV linden female mouse showing carcinoma in situ, associated with marked dermal inflammatory infiltrate; d. liver of HPV linden mouse showing focal hepatocyte necrosis, associated with neutrophil infiltrate. Hematoxylin and eosin staining.

Small necrotic areas were rarely observed in HPV animals exposed to linden (Fig. 3). The spleen was characterized by extramedullary haematopoiesis and mild to moderate lymphoid hyperplasia, with no differences between the groups. Regarding hepatic stress analysis, the only significant change was observed in the female for CAT activity, with a decrease in the HPV female mice compared to the wild-type mice nonexposed to linden extract $(p<0.05)$. In the renal oxidative stress analysis, the only significant change was observed in the male for CAT activity, with an increase in the wild-type mice exposed to linden extract compared to the wild-type mice nonexposed to linden extract $(p<0.05)$ (Table 6). 
Table 5 Number of animals (\%) with histological liver and kidney lesions

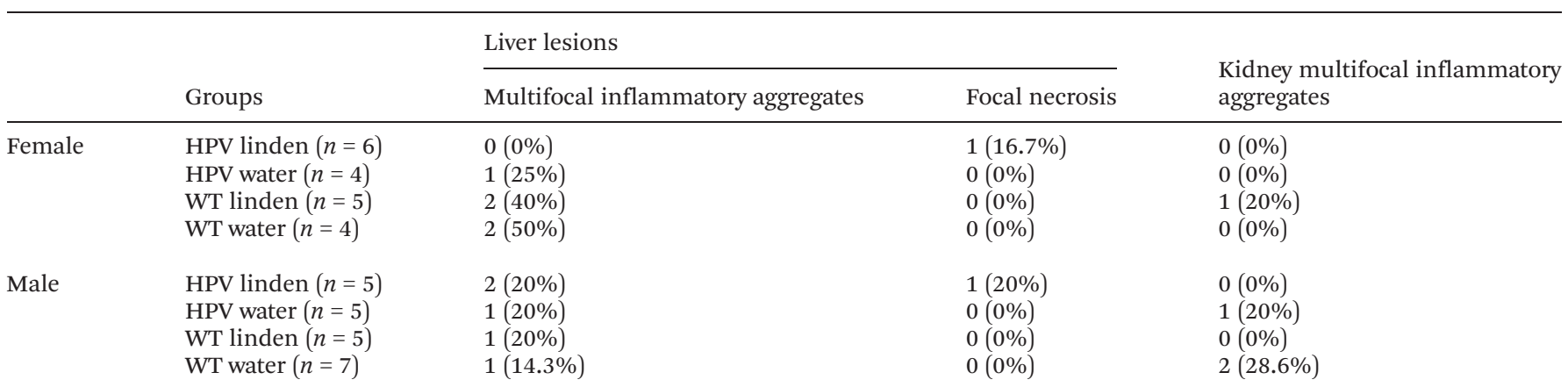

Statistically significant differences were not found.

Table 6 Oxidative stress parameters evaluated in the liver and kidneys in the experimental groups (mean \pm standard error)

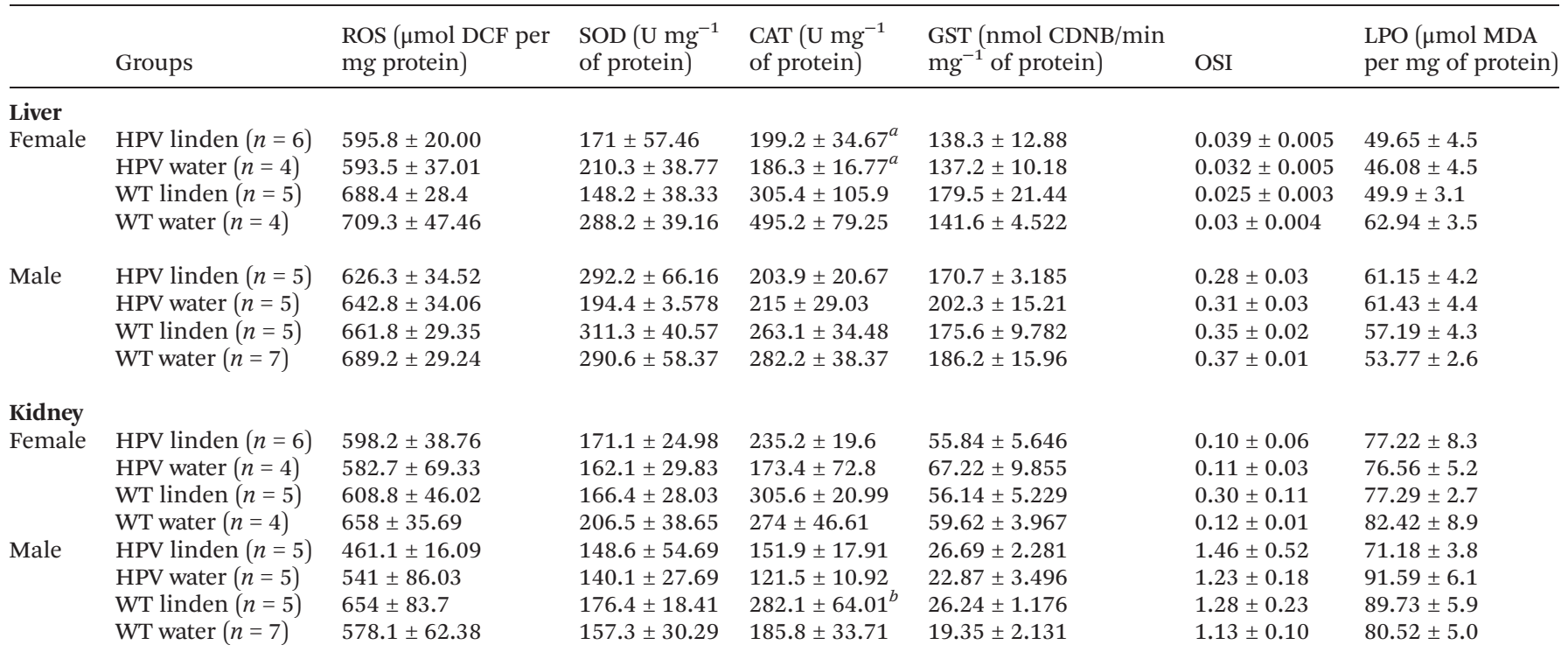

${ }^{a}$ Statistically different from the WT water female group $(p<0.05) .{ }^{b}$ Statistically different from the WT water male group $(p<0.05)$.

\section{Discussion}

A K14HPV16 transgenic mouse model is useful for studying HPV-induced carcinogenesis. The animals expressed HPV16 oncogenes by cytokeratin-14 human (K14) promoter development of viral lesions. ${ }^{15}$ The lesions are morphologically and molecularly similar to lesions in HPV-related human disease. ${ }^{29}$ Recently, several natural products were tested by our team using the K14HPV16 transgenic mouse model, such as curcumin and rutin, ${ }^{30}$ ptaquiloside from bracken, ${ }^{31}$ laurel $^{19}$ and the red seaweed Phorphyra umbilicalis. ${ }^{32}$ Numerous natural compounds have been shown to promote health due to their therapeutic and chemopreventive properties. ${ }^{33}$ Yayalaci and collaborators used a rat model with ethanol-induced oxidative stress, to investigate the antioxidant activity of an aqueous extract obtained from linden flowers. ${ }^{5}$ Their results indicated that linden flowers did not protect against alcohol-induced liver injury and oxidative stress. ${ }^{5}$ In the present study, we evaluated the potential in vivo toxicity of the extract of T. platyphyllos Scop. and its chemopreventive effects against the cutaneous lesions of this transgenic mouse model. All animals survived to the experimental protocol and no changes in their mean body weights were observed. The male wild-type groups showed a positive weight gain which was not impacted by the extract. Female animals showed stable weights or slight weight losses during the experimental period, and the linden extract was not associated with significant weight differences. However, the male HPV-transgenic mice exposed to linden showed a significant lower weight gain compared with matched untreated animals. These results suggest that the extract is safe among wild-type mice, but its impact on the growth of HPV-transgenic mice requires additional investigation. The weight gain differences could not be explained by different food intake, which was similar among all groups. Transgenic mice showed higher water intake, as previously described by our group. ${ }^{30}$ No association with the extract could 
be established, which could indicate low palatability leading to reduced water consumption and dehydration. As previously described, HPV-transgenic animals showed retarded growth, in association with chronic hepatitis and systemic inflammation. ${ }^{30}$ So, the next analyses were designed to investigate whether the linden extract could increase liver damage in HPV16-transgenic mice, especially among male animals, thereby interfering with animals' growth. ALT and AST levels, widely used as serum markers of hepatic damage, ${ }^{34}$ were not consistently elevated in association with administration of the linden extract. Histological analysis demonstrated the presence of multifocal inflammatory aggregates, especially in the liver, but no significant changes were observed between the groups, suggesting that the linden extract was not hepatotoxic in this model. In line with these findings, the relative weights of the liver and spleen and the microhematocrit values showed no significant changes between the groups, supporting the hypothesis that the linden extract is safe under the present experimental conditions. High levels of blood urea and creatinine are indicators of kidney dysfunction. ${ }^{35}$ In the present experiment, the urea and creatinine levels were similar in the groups, although a single nephritis was observed in lindenexposed wild-type females. Oxidative stress analysis did not reveal any statistically significant differences that could be associated with the oral administration of the linden extract. These results agree with the previous findings and help defining a favourable toxicological profile for the linden extract. This animal model is associated with the development of cutaneous lesions induced by HPV16 that begins with hyperplastic lesions, progressing to dysplastic lesions or even evolving to carcinoma in situ. ${ }^{15,18}$ The linden extract was associated with approximately $20 \%$ reduction on the incidence of epidermal dysplasia, which did not reach statistical significance. In this animal model, other substances with anti-inflammatory properties, including flavonoids, were able to reduce the infiltration of leukocytes, modulate the expression of cyclooxigenase-2, increase the activity of cytotoxic lymphocytes and significantly block the development of HPV16-induced epidermal lesions at the hyperplastic stage. ${ }^{19,36-39}$ The present results do not provide conclusive evidence to support a chemopreventive role of the linden extract in this model and additional studies are required to test the efficacy of higher extract doses.

\section{Conclusions}

The consumption of T. platyphyllos Scop. was well tolerated by K14HPV16 mice, with no associated significant liver or kidney damage, supporting the hypothesis that this extract has a favourable toxicological profile. The results from this study suggest that the T. platyphyllos Scop. extract has minimal or null chemopreventive effects against HPV16-induced skin lesions in this animal model. Future studies should investigate the functions of the extract's major bioactive components, such as protocatechuic acid and (-)-epicatechin. Additional studies on this subject should employ high dosages, test par- enteral administration routes or for prolonged administration periods.

\section{Author contributions}

T.F., E.N.G., S.M. and I.B. conducted the experiments with live animals, sacrifice and sample processing. T.F. and E.N.G wrote the manuscript; A.G. performed histology analysis; R.M.G.d.C and P.A.O. designed the experiments and supervised; G.L., F.L. C.V. performed oxidative stress analysis; I.G. and A.A. wrote the manuscript; M.J.P. participated in the sacrifice of animals and determined microhematocrit; M.M.S.M.B. and R.M. participated in animal sacrifice and wrote the manuscript; A.N., L. B. and I. C. F. R. Ferreira performed Tilia platyphyllos Scop. extract preparation and characterization and wrote the manuscript; E.R. and P.A.O. funding.

\section{Funding}

This work was supported by the project IBERPHENOL, project number 0377_IBERPHENOL_6_E; Interact R\&D project, operation number NORTE-01-0145-FEDER-000017, National Funds by FCT - Portuguese Foundation for Science and Technology, under the project UIDB/04033/2020 (CITAB), and project UIDB/ CVT/00772/2020 (CECAV) and the post-graduation grant SFRH/ $\mathrm{BD} / 136747 / 2018$ and 2020.04789.BD; the authors are also grateful to FCT, Portugal and FEDER under programme PT2020 for financial support to CIMO (UIDB/00690/2020) and L. Barros acknowledges the national funding by FCT, P. I., through the institutional scientific employment program-contract. The authors would like to thank Cantinho das Aromáticas organic farmers from Vila Nova de Gaia (Portugal) for providing the samples. This work was financially supported by: Base Funding - UIDB/00511/2020 of the Laboratory for Process Engineering, Environment, Biotechnology and Energy LEPABE - funded by national funds through the FCT/MCTES (PIDDAC).

\section{Conflicts of interest}

The authors declare no conflict of interest.

\section{References}

1 E. Eaton, G. Caudullo and D. de Rigo, in European atlas of forest tree species, Publications Office of the European Union, Luxembourg, 2016, pp. 184-185.

2 L. Galiano, G. Timofeeva, M. Saurer, R. Siegwolf, J. Martínez-Vilalta, R. Hommel and A. Gessler, Plant, Cell Environ., 2017, 40, 1711-1724.

3 I. Jabeur, N. Martins, L. Barros, R. C. Calhelha, J. Vaz, L. Achour, C. Santos-Buelga and I. C. F. R. Ferreira, Food Funct., 2017, 8, 975-984. 
4 V. Chalupa, J. For. Sci., 2012, 49, 537-543.

5 Y. Yayalaci, I. Celik and B. Batı, J. Membr. Biol., 2014, 247, 181-188.

6 T. Tanaka, T. Tanaka and M. Tanaka, J. Exp. Clin. Med., 2011, 3, 27-33.

7 Y. Hirose, T. Tanaka, T. Kawamori, M. Olnishi, H. Makita, H. Mori, K. Satoh and A. Hara, Carcinogenesis, 1995, 16, 2337-2342.

8 T. H. Tseng, J.-D. Hsu, M.-H. Lo, C.-Y. Chu, F.-P. Chou, C.-L. Huang and C.-J. Wang, Cancer Lett., 1998, 126, 199207.

9 M. Prakash, B. V. Basavaraj and K. N. Chidambara Murthy, J. Funct. Foods, 2019, 52, 14-24.

10 D. Estêvão, N. R. Costa, R. M. Gil da Costa and R. Medeiros, Biochim. Biophys. Acta, Gene Regul. Mech., 2019, 1862, 153-162.

11 R. Faridi, A. Zahra, K. Khan and M. Idrees, Virol. J., 2011, 8, 269.

12 J. Doorbar, N. Egawa, H. Griffin, C. Kranjec and I. Murakami, Rev. Med. Virol., 2015, 25, 2-23.

13 R. B. S. Roden and P. L. Stern, Nat. Rev. Cancer, 2018, 18, 240-254.

14 V. M. Williams, M. Filippova, U. Soto and P. J. DuerksenHughes, Future Virol., 2011, 6, 45-57.

15 J. Arbeit, K. Münger, P. Howley and D. Hanahan, J. Virol., 1994, 68, 4358-4368.

16 S. M. F. Bessada, J. C. M. Barreira, L. Barros, I. C. F. R. Ferreira and M. B. P. P. Oliveira, Ind. Crops Prod., 2016, 89, 45-51.

17 D. Forbes, H. J. M. Bloom, N. Kostomitsopoulos, G. Moore and G. Perretta, Euroguide: on the accommodation and care of animals used for experimental and other scientific purposes; (based on the revised Appendix A of the European Convention ETS 123), FELASA, London, 2007.

18 R. Araújo, J. M. O. Santos, M. Fernandes, F. Dias, H. Sousa, J. Ribeiro, M. M. S. M. Bastos, P. A. Oliveira, D. Carmo, F. Casaca, S. Silva, R. Medeiros and R. M. Gil da Costa, J. Cancer Res. Clin. Oncol., 2018, 144, 241-248.

19 B. Medeiros-Fonseca, V. F. Mestre, B. Colaço, M. J. Pires, T. Martins, R. M. Gil da Costa, M. J. Neuparth, R. Medeiros, M. S. S. Moutinho, M. I. Dias, L. Barros, M. M. S. M. Bastos, L. Félix, C. Venâncio, I. C. F. R. Ferreira, L. M. Antunes and P. A. Oliveira, Food Funct., 2018, 9, 4419-4428.

20 L. M. Félix, A. M. Vidal, C. Serafim, A. M. Valentim, L. M. Antunes, S. M. Monteiro, M. Matos and A. M. Coimbra, Chemosphere, 2018, 201, 730-739.

21 G. A. B. Lanzarin, L. M. Félix, D. Santos, C. A. S. Venâncio and S. M. Monteiro, Chemosphere, 2019, 223, 514-522.

22 L. M. Félix, A. M. Vidal, C. Serafim, A. M. Valentim, L. M. Antunes, S. Campos, M. Matos, S. M. Monteiro and A. M. Coimbra, RSC Adv., 2016, 6, 61254-61266.

23 I. Durak, Z. Yurtarslanl, O. Canbolat and Ö. Akyol, Clin. Chim. Acta, 1993, 214, 103-104.
24 H. Aebi, in Methods Enzymol, Elsevier, 1984, vol. 105, pp. 121-126.

25 W. H. Habig and W. B. Jakoby, in Methods Enzymol, Academic Press, 1981, vol. 77, pp. 398-405.

26 G. Sotiris, N. Patsoukis, D. Nikolopoulos and C. Georgiou, Eye, 2007, 21, 1406-1411.

27 B. Wallin, B. Rosengren, H. G. Shertzer and G. Camejo, Anal. Biochem., 1993, 208, 10-15.

28 R. Arantes-Rodrigues, A. Henriques, M. J. Pires, B. Colaço, A. M. Calado, P. Rema, A. Colaço, T. Fernandes, P. L. F. De la Cruz, C. Lopes, L. Fidalgo-Gonçalves, S. Vilela, T. Pedrosa, F. Peixoto and P. A. Oliveira, Food Chem. Toxicol., 2011, 49, 1989-1997.

29 K. Smith-McCune, Y. H. Zhu, D. Hanahan and J. Arbeit, Cancer Res., 1997, 57, 1294-1300.

30 R. M. Gil da Costa, S. Aragão, M. Moutinho, A. Alvarado, D. Carmo, F. Casaca, S. Silva, J. Ribeiro, H. Sousa, R. Ferreira, R. Nogueira-Ferreira, M. J. Pires, B. Colaço, R. Medeiros, C. Venâncio, M. M. Oliveira, M. M. S. M. Bastos, C. Lopes and P. A. Oliveira, Life Sci., 2017, 169, 11-19.

31 C. Santos, P. Ferreirinha, H. Sousa, J. Ribeiro, M. M. S. M. Bastos, T. Neto, P. A. Oliveira, R. Medeiros, M. Vilanova and R. M. Gil da Costa, Food Chem. Toxicol., 2016, 97, 277-285.

32 S. Santos, T. Ferreira, J. Almeida, M. J. Pires, A. Colaço, S. Lemos, R. M. Gil da Costa, R. Medeiros, M. M. S. M. Bastos, M. J. Neuparth, H. Abreu, R. Pereira, M. Pacheco, I. Gaivão, E. Rosa and P. A. Oliveira, Mar. Drugs, 2019, 17, 615.

33 T. Ferreira, E. Nascimento-Gonçalves, R. M. Gil Da Costa, E. Rosa and P. A. Oliveira, World Acad. Sci. J., 2020, 2 , 9.

34 P. T. Giboney, Am. Fam. Physician, 2005, 71, 11051110.

35 S. Gowda, P. B. Desai, S. S. Kulkarni, V. V. Hull, A. A. K. Math and S. N. Vernekar, N. Am. J. Med. Sci., 2010, 2, 170-173.

36 C. Santos, T. Neto, P. Ferreirinha, H. Sousa, J. Ribeiro, M. M. S. M. Bastos, A. I. Faustino-Rocha, P. A. Oliveira, R. Medeiros, M. Vilanova and R. M. G. da Costa, Life Sci., 2016, 157, 67-73.

37 M. Moutinho, S. Aragão, D. Carmo, F. Casaca, S. Silva, J. Ribeiro, H. Sousa, I. Pires, F. Queiroga, B. Colaço, R. Medeiros, P. A. Oliveira, C. Lopes, M. Bastos and Da Costa, Anticancer Res., 2018, 38(3), 1461-1466.

38 T. Ferreira, S. Campos, M. G. Silva, R. Ribeiro, S. Santos, J. Almeida, M. J. Pires, R. M. Gil da Costa, C. Córdova, A. Nogueira, M. J. Neuparth, R. Medeiros, M. M. S. M. Bastos, I. Gaivão, F. Peixoto, M. M. Oliveira and P. A. Oliveira, Int. J. Mol. Sci., 2019, 20, 3902.

39 J. M. O. Santos, A. Moreira-Pais, T. Neto, S. Peixoto da Silva, P. A. Oliveira, R. Ferreira, J. Mendes, M. M. S. M. Bastos, C. Lopes, F. Casaca, S. Silva, C. Sweeney, R. Medeiros and R. M. Gil da Costa, Drug Dev. Res., 2019, 80, 824-830. 